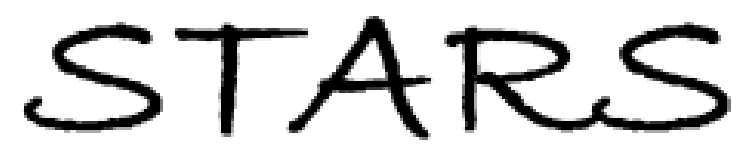

University of Central Florida

STARS

$1-1-2007$

\title{
Criterion for predicting the glass-forming ability of alloys
}

\author{
S. Sharma \\ University of Central Florida \\ R. Vaidyanathan \\ University of Central Florida \\ C. Suryanarayana \\ University of Central Florida
}

Find similar works at: https://stars.library.ucf.edu/facultybib2000

University of Central Florida Libraries http://library.ucf.edu

This Article is brought to you for free and open access by the Faculty Bibliography at STARS. It has been accepted for inclusion in Faculty Bibliography 2000 s by an authorized administrator of STARS. For more information, please contact STARS@ucf.edu.

\section{Recommended Citation}

Sharma, S.; Vaidyanathan, R.; and Suryanarayana, C., "Criterion for predicting the glass-forming ability of alloys" (2007). Faculty Bibliography 2000s. 7639.

https://stars.library.ucf.edu/facultybib2000/7639

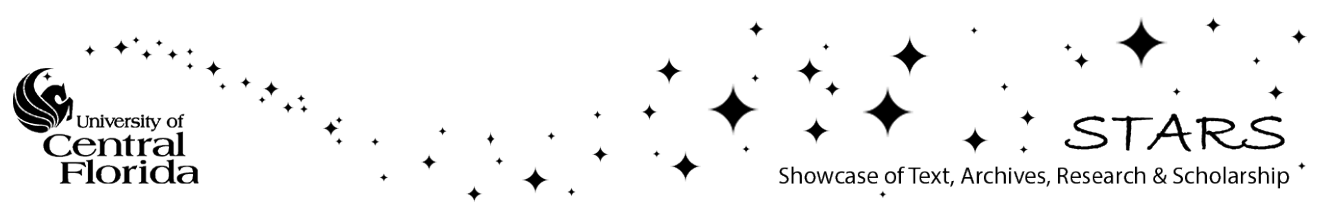




\section{Criterion for predicting the glass-forming ability of alloys}

Cite as: Appl. Phys. Lett. 90, 111915 (2007); https://doi.org/10.1063/1.2713867

Submitted: 10 December 2006 . Accepted: 12 February 2007 . Published Online: 16 March 2007

S. Sharma, R. Vaidyanathan, and C. Suryanarayana

\section{ARTICLES YOU MAY BE INTERESTED IN}

New criterion of glass forming ability for bulk metallic glasses

Journal of Applied Physics 101, 086108 (2007); https://doi.org/10.1063/1.2718286

Prediction of glass-forming ability of metallic liquids

Applied Physics Letters 91, 221910 (2007); https://doi.org/10.1063/1.2801517

Binary $\mathrm{Ni}-\mathrm{Nb}$ bulk metallic glasses

Journal of Applied Physics 99, 026103 (2006); https://doi.org/10.1063/1.2158130

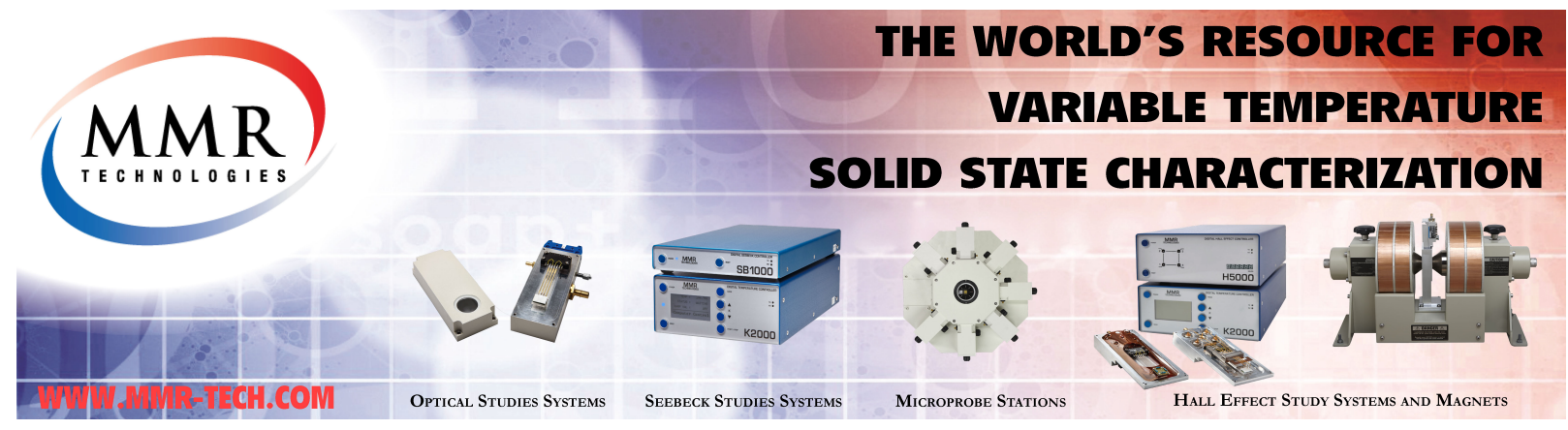




\title{
Criterion for predicting the glass-forming ability of alloys
}

\author{
S. Sharma, R. Vaidyanathan, and C. Suryanarayana ${ }^{a)}$ \\ Department of Mechanical, Materials and Aerospace Engineering, University of Central Florida, Orlando, \\ Florida 32816-2450
}

(Received 10 December 2006; accepted 12 February 2007; published online 16 March 2007)

\begin{abstract}
Mechanical alloying (MA) of blended elemental powder mixtures of $\mathrm{Fe}_{42} \mathrm{Zr}_{10} X_{28} \mathrm{~B}_{20}(X=\mathrm{Al}, \mathrm{Co}$, $\mathrm{Ge}, \mathrm{Mn}, \mathrm{Ni}$, and $\mathrm{Sn}$ ) was carried out to determine their glass-forming ability (GFA) (as determined by the time required to form the amorphous phase). During milling, amorphization was achieved in systems with $X=\mathrm{Al}, \mathrm{Ge}$, or $\mathrm{Ni}$, but not in the other systems. The GFA could be correlated with the total number of intermetallics present in the constituent binary phase diagrams. Thus, this work offers the equilibrium phase diagram as a predictive tool to determine if amorphization can be achieved by the MA method. (C) 2007 American Institute of Physics. [DOI: 10.1063/1.2713867]
\end{abstract}

Metallic glasses have an attractive combination of physical, chemical, and mechanical properties attributed to their atomic structure. ${ }^{1-4}$ While high solidification rates (about $10^{6} \mathrm{~K} / \mathrm{s}$ ) were required to produce metallic glasses from the liquid state in the form of thin ribbons, it has been possible to reduce the critical cooling rate required to form metallic glasses to as low as $1 \mathrm{~K} / \mathrm{s}$ by optimizing the nature of the constituent elements and alloy composition. Consequently, the section thickness has been increased to several tens of millimeters, and these are referred to as bulk metallic glasses. ${ }^{5-10}$ Several attempts have been made to understand the mechanism of amorphization and to determine the criteria for glass formation in order to predict alloy compositions that possess high glass-forming ability (GFA). One of the earliest criteria proposed was that an alloy with a high reduced glass transition temperature $\left(T_{\mathrm{rg}}\right)$ defined as $T_{\mathrm{rg}}$ $=T_{g} / T_{l}$, where $T_{g}$ is the glass transition temperature and $T_{l}$ is the liquidus/melting temperature, exhibits a high GFA.11,12 Other criteria have also been proposed in recent years. ${ }^{13-16}$

It has not been possible to obtain large section thicknesses in Fe-based bulk metallic glasses through the solidification route; the maximum reported is about $16 \mathrm{~mm} .{ }^{17}$ Since mechanical alloying (MA) has been known to be an efficient method to synthesize amorphous alloy powders, ${ }^{18,19}$ our objective was to produce large sections of amorphous Fe-based alloys by this method. This has been proven feasible by producing amorphous Fe-based alloy powders through high-energy ball milling and by consolidating them to different section thicknesses. ${ }^{20}$ In the course of these investigations, we have identified a simple criterion to determine the GFA of alloy systems.

A number of quaternary alloy compositions based on $\mathrm{Fe}$ and with the general composition $\mathrm{Fe}_{42} X_{28} \mathrm{Zr}_{10} \mathrm{~B}_{20}$ (where $X$ $=\mathrm{Al}, \mathrm{Co}, \mathrm{Ge}, \mathrm{Mn}, \mathrm{Ni}$, or $\mathrm{Sn}$ ) were selected for the present study. The element $X$ was selected based on the number of intermetallics it forms with $\mathrm{Zr}$ under equilibrium conditions at room temperature. ${ }^{21}$ This number increases from 1 with $\mathrm{Mn}$ to 8 with $\mathrm{Al}$, which provides a basis to analyze the results systematically. Further, the negative heat of formation of the intermetallics with $\mathrm{Zr}$ is much higher than that with either $\mathrm{Fe}$ or $\mathrm{B}{ }^{22}$ Thus, the probability of forming an intermetallic with $\mathrm{Zr}$ during milling is higher than with $\mathrm{Fe}$ or $\mathrm{B}$.

\footnotetext{
a) Author to whom correspondence should be addressed; electronic mail:
} csuryana@mail.ucf.edu
Pure elemental powders of $>99.9 \%$ purity were blended together for each alloy system, and MA was carried out in a high-energy SPEX CertiPrep 8000 D shaker mill using hardened steel balls, maintaining a ball-to-powder weight ratio of 10:1. The weighing, blending, loading, and unloading of powders were carried out inside a glove box filled with a controlled atmosphere of argon, so as to minimize powder contamination. The phase evolution during milling was monitored by $\mathrm{x}$-ray diffraction (XRD).

Figure 1 shows the XRD patterns of the blended elemental (BE) powder mixture of $\mathrm{Fe}_{42} \mathrm{Al}_{28} \mathrm{Zr}_{10} \mathrm{~B}_{20}$ as a function of milling time. It is noted that amorphization has commenced after about $10 \mathrm{~h}$ of milling, as evidenced by the presence of a broad diffuse peak at the position of the $(110)_{\mathrm{Fe}}$ peak. This broad diffuse peak continued to be present until about $40 \mathrm{~h}$ of milling, suggesting that the amorphous phase produced is quite stable. However, on milling this amorphous powder further, this diffuse peak started to become sharp. On continued milling, some additional sharp peaks appeared, suggesting that the previously formed amorphous phase had crystallized, a phenomenon referred to as mechanical crystallization. ${ }^{20}$ But during the early stages of milling, e.g., less than $10 \mathrm{~h}$, the XRD patterns clearly showed evidence of formation of the intermetallic phases in the milled

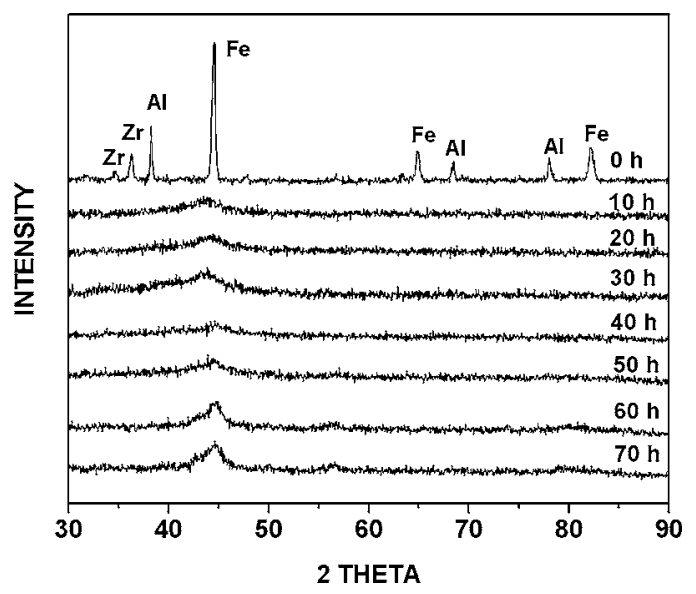

FIG. 1. XRD patterns of blended elemental powder mix of $\mathrm{Fe}_{42} \mathrm{Al}_{28} \mathrm{Zr}_{10} \mathrm{~B}_{20}$ as a function of milling time. Note that the amorphous phase has started to form on milling for about $10 \mathrm{~h}$ and that the amorphous phase was stable up to about $40 \mathrm{~h}$. Milling beyond this time resulted in mechanical crystallization of the amorphous powder. 


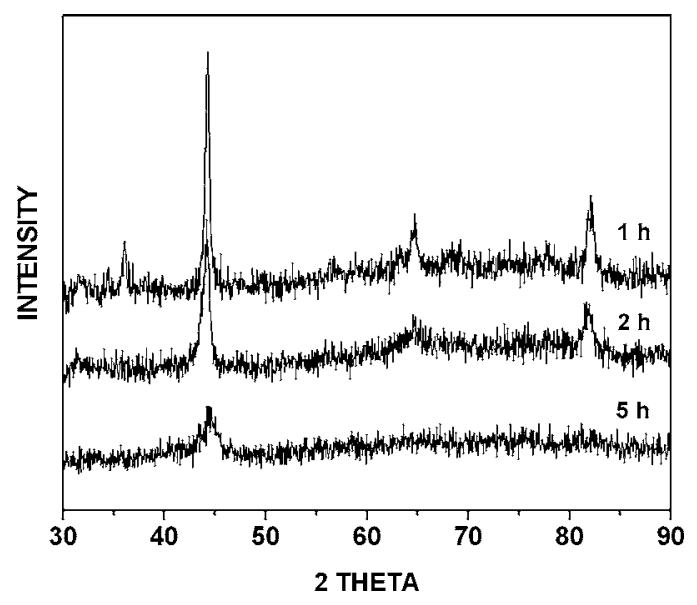

FIG. 2. XRD patterns of blended elemental powder mix of $\mathrm{Fe}_{42} \mathrm{Al}_{28} \mathrm{Zr}_{10} \mathrm{~B}_{20}$ at early times of milling. Note that formation of intermetallics is observed during early hours of milling. At longer milling times, e.g., more than $10 \mathrm{~h}$, an amorphous phase begins to form (Fig. 1).

$\mathrm{Fe}_{42} \mathrm{Al}_{28} \mathrm{Zr}_{10} \mathrm{~B}_{20}$ powder (Fig. 2). Similar observations of amorphous phase formation on milling the BE powder mixtures were additionally noted in alloy systems with $X=\mathrm{Ge}$ and $\mathrm{Ni}$.

Figure 3 shows the XRD patterns of the $\mathrm{Fe}_{42} \mathrm{Co}_{28} \mathrm{Zr}_{10} \mathrm{~B}_{20}$ powder mix as a function of milling time. In contrast to the above results, an amorphous phase did not form in the Cocontaining alloy. Instead, only a solid solution phase was obtained on milling for $10 \mathrm{~h}$, which continued to be stable even up to $30 \mathrm{~h}$ of milling. Similarly, amorphization was not achieved in powder blends containing Mn and Sn.

The phase formation sequence in all the six powder blends can be summarized into three groups:

(1) BE powder $\rightarrow$ Intermetallics $\rightarrow$ Solid solution

Examples: Mn- and Sn-containing systems,

(2) BE powder $\rightarrow$ Solid solution

Example: Co-containing system,

(3) BE powder $\rightarrow$ Intermetallics $\rightarrow$ Amorphous phase $\rightarrow$

(Mechanical) Crystallization

Examples: Al-, Ge-, and Ni-containing systems.

The time required for amorphization, which can be considered a measure of the GFA of the alloy, is also different for different powder blends. Table I summarizes the results obtained in this investigation, including the equilibrium number of intermetallics present between $X$ and the constituent elements ( $\mathrm{Zr}, \mathrm{Fe}$, or B) in the powder blend.

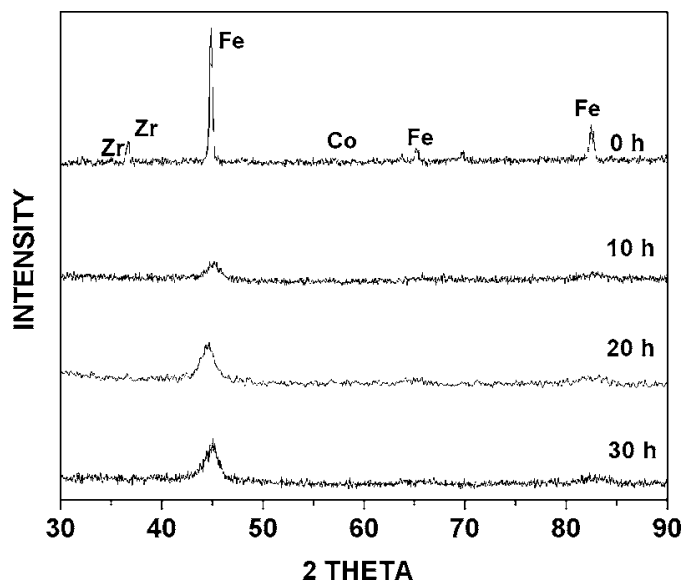

FIG. 3. XRD patterns of $\mathrm{Fe}_{42} \mathrm{Co}_{28} \mathrm{Zr}_{10} \mathrm{~B}_{20}$ powder mix as a function of milling time. Note that an amorphous phase had not formed in this case; instead, only a solid solution phase was obtained on milling for $30 \mathrm{~h}$.

Let us now look at the reasons for the formation of an amorphous phase in some select systems and not in all. A close examination of Table I clearly reveals that the ease of amorphization (i.e., GFA) increases with the number of intermetallics present in the constituent $\mathrm{Zr}-\mathrm{X}$ binary phase diagrams. This is apparent from the powder blends containing $\mathrm{Al}$ or $\mathrm{Ni}$, which amorphize in 10 or $20 \mathrm{~h}$, respectively. While the quaternary $\mathrm{Fe}-\mathrm{Zr}-\mathrm{Al}-\mathrm{B}$ contains eight intermetallic phases in the binary system between $\mathrm{Zr}$ and $\mathrm{Al}$, the $\mathrm{Fe}-\mathrm{Zr}-$ $\mathrm{Ni}-\mathrm{B}$ contains seven intermetallic phases in the binary system between $\mathrm{Zr}$ and Ni. Similarly, the Ge-containing system which also amorphizes in $10 \mathrm{~h}$, contains five intermetallics between $\mathrm{Zr}$ and $\mathrm{Ge}$. The $\mathrm{Zr}-\mathrm{Co}, \mathrm{Zr}-\mathrm{Sn}$, and $\mathrm{Zr}-\mathrm{Mn}$ binary systems which do not show amorphization contain five, three, and one intermetallics, respectively.

The situation is, however, different when we consider the total number of intermetallics present in all the constituent binary alloy systems. Thus, in the glass-forming systems, the total number of intermetallics present in all the constituent binary alloy systems is more than 10 . For example, the total number of intermetallics between element $X$ and $\mathrm{Zr}, \mathrm{Fe}$, or B is 15 (maximum) in the system containing $\mathrm{Al}$, followed by $\mathrm{Ni}$ with 12 . Amorphization of Ge-containing alloy, with a total of ten intermetallics, is explained by the fact that $\mathrm{Ge}$ is semimetallic in nature with a covalent bonding and therefore has an easy tendency to amorphize compared to other elements. Accordingly, it is noted that when the total number of intermetallics is $\geqslant 10$, amorphization is observed in the systems. If it is less than this, amorphous phase formation is not

TABLE I. Summary of the results of amorphization including the number of intermetallics between the element $X$ and $\mathrm{Zr}, \mathrm{Fe}$, or $\mathrm{B}$.

\begin{tabular}{|c|c|c|c|c|c|}
\hline \multirow[b]{2}{*}{$X$} & \multicolumn{3}{|c|}{ Number of intermetallics between $X$ and $\mathrm{Zr}$} & \multirow{2}{*}{$\begin{array}{c}\text { Total number of } \\
\text { intermetallics }\end{array}$} & \multirow{2}{*}{$\begin{array}{l}\text { Milling time } \\
\text { required for } \\
\text { amorphization } \\
\text { (h) }\end{array}$} \\
\hline & $X$ and $\mathrm{Zr}$ & $X$ and $\mathrm{Fe}$ & $X$ and B & & \\
\hline $\mathrm{Mn}$ & 1 & Nil & 5 & 6 & No amorphization \\
\hline $\mathrm{Sn}$ & 3 & 2 & Nil & 5 & No amorphization \\
\hline Co & 5 & Nil & 3 & 8 & No amorphization \\
\hline $\mathrm{Ge}$ & 5 & 5 & Nil & 10 & 10 \\
\hline $\mathrm{Ni}$ & 7 & 1 & 4 & 12 & 20 \\
\hline $\mathrm{Al}$ & 8 & 5 & 2 & 15 & 10 \\
\hline
\end{tabular}


TABLE II. Representative maximum energy contributed by different crystalline defects.

\begin{tabular}{ll}
\hline \hline \multicolumn{1}{c}{ Type of defect } & Maximum energy $(\mathrm{kJ} /$ mole of atoms $)$ \\
\hline Dislocation $\left(10^{16} / \mathrm{m}^{2}\right)$ & 1 \\
Grain size $(1 \mathrm{~nm})$ & 10 \\
Disordering & 12 \\
Vacancies $(1 \%)$ & 1 \\
\hline \hline
\end{tabular}

observed. At this stage, we cannot attribute a specific reason for this number, 10 , except to mention that the greater the number of intermetallics in the system, the easier it is for it to amorphize.

Another important point may be noted from an observation of the constituent binary phase diagrams in these alloy systems. If the $\mathrm{Fe}-X$ binary phase diagram shows the presence of a solid solution phase at room temperature, amorphization is inhibited. This has been found to be true in $\mathrm{Fe}-$ $\mathrm{Co}, \mathrm{Fe}-\mathrm{Mn}$, and $\mathrm{Fe}-\mathrm{Sn}$ binary alloy systems.

Let us now look at the possible reasons for the relationship between the presence of intermetallics or solid solution in the phase diagrams and the formation of an amorphous phase. As has been discussed in the literature, ${ }^{18,19,23,24}$ the reason for the formation of an amorphous phase in powder blends subjected to heavy deformation is the increase in free energy of the system by storage of energy. That is, the energy contributions by crystal defects generated by heavy deformation increase the free energy of the crystalline phase above that of the hypothetical amorphous phase. Thus, amorphization occurs when $G_{C}+G_{D}>G_{A}$, where $G_{C}=$ free energy of the crystalline phase, $G_{D}=$ free energy increase due to defects, and $G_{A}=$ free energy of the amorphous phase. Consequently, due to accumulation of defects, the crystalline phase becomes destabilized and the amorphous phase becomes stable. However, once the solid solution phase forms, it becomes difficult to store sufficient energy into the system so as to increase it above that of the amorphous phase. Then, formation of an amorphous phase becomes impossible.

During MA, a variety of crystal defects including dislocations, grain boundaries, stacking faults, antiphase boundaries, etc., are introduced into the alloy, and the rate of defect production controls the kinetics of amorphization. Intermetallics are generally line compounds having a narrow composition range. Thus, a slight deviation from stoichiometry can result in a large rise in the free energy of the system. When material transfer occurs due to disordering of the lattice, the free energy will increase further, thus favoring amorphization. The free energy change associated with the crystalline to amorphous transformation is typically about $5-20 \mathrm{~kJ} \mathrm{~mol}^{-1}$. $^{24}$

The relative contributions of the different defects to raise the free energy of the system are different, and their values are summarized in Table II. ${ }^{25}$ It can be clearly seen that the maximum contribution comes from the creation of additional grain boundaries (i.e., formation of nano- or ultrafine-grained material) and disordering introduced into the intermetallic phase by the process of heavy deformation. ${ }^{25}$ Thus, the maximum increase in free energy arises from creating additional grain boundaries and from the disordering of intermetallics present in the system, and this contributes to the amorphization of the system. On the other hand, when a solid solution forms during milling, the only defects that can be introduced into the system are dislocations and grain boundaries, and thus the energy increase is much less than what can be achieved in an intermetallic. Consequently, amorphous phase formation becomes difficult once a solid solution phase had formed. Further, the disorder induced in an alloy during MA is comparable to the disorder caused by an increase in temperature of the same alloy. ${ }^{18,19}$ Thus, during milling, the effective temperature of the system can be considered to have increased from ambient to an elevated temperature.

From the above analysis it can be concluded that by observing the equilibrium phase diagrams it is possible to predict whether a system can form an amorphous phase during MA or not. If the alloy system contains a solid solution phase over a wide composition range, amorphization is not possible. On the other hand, when a large number of intermetallics are present, amorphization is easy. This has been demonstrated with a number of alloy systems.

The authors thank the National Science Foundation for their financial support under Grant No. NSF-DMR-0314212.

${ }^{1}$ Amorphous Metallic Alloys, edited by F. E. Luborsky (Butterworths, London, 1983).

${ }^{2}$ Metallic Glasses, edited by T. R. Anantharaman (TransTech, Zurich, Switzerland, 1984).

${ }^{3}$ H. J. Güntherödt and H. Beck, Glassy Metals (Springer, Berlin, 1981), Vol. I; (Springer, Berlin, 1983), Vol. II; (Springer, Berlin, 1994), Vol. III.

${ }^{4}$ Rapidly Solidified Alloys, edited by H. H. Liebermann (Dekker, New York, 1993).

${ }^{5}$ A. Inoue, Acta Mater. 48, 279 (2000).

${ }^{6}$ A. Inoue, Bulk Amorphous Alloys: Preparation and Fundamental Characteristics, Materials Science Foundations Vol. 4 (TransTech, Zurich, Switzerland, 1998).

${ }^{7}$ W. L. Johnson, MRS Bull. 24, 42 (1999).

${ }^{8}$ J. F. Löffler, Intermetallics 11, 529 (2003).

${ }^{9}$ W. H. Wang, C. Dong, and C. H. Shek, Mater. Sci. Eng., R. 44, 45 (2004).

${ }^{10}$ J. Schroers and W. L. Johnson, Phys. Rev. Lett. 93, 255506 (2004).

${ }^{11}$ D. Turnbull, Contemp. Phys. 10, 473 (1969).

${ }^{12}$ D. Xu, G. Duan, and W. L. Johnson, Phys. Rev. Lett. 92, 245504 (2004).

${ }^{13}$ D. Xu, B. Lohwongwatana, G. Duan, W. L. Johnson, and C. Garland, Acta Mater. 52, 2621 (2004).

${ }^{14}$ L. Xia, W. H. Li, S. S. Fang, B. C. Wei, and Y. D. Dong, J. Appl. Phys. 99, 026103 (2006).

${ }^{15}$ L. Xia, D. Ding, S. T. Shan, and Y. D. Dong, J. Phys.: Condens. Matter 18, 3543 (2006).

${ }^{16}$ Z. P. Lu and C. T. Liu, Phys. Rev. Lett. 91, 115505 (2003).

${ }^{17}$ J. Shen, Q. Chen, J. Sun, H. Fan, and G. Wang, Appl. Phys. Lett. 86, 151907 (2005).

${ }^{18}$ C. Suryanarayana, Prog. Mater. Sci. 46, 1 (2001).

${ }^{19}$ C. Suryanarayana, Mechanical Alloying and Milling (Dekker, New York, 2004).

${ }^{20}$ U. Patil, S. J. Hong, and C. Suryanarayana, J. Alloys Compd. 389, 121 (2005).

${ }^{21}$ T. B. Massalski, Binary Alloy Phase Diagrams (ASM International, Materials Park, OH, 1986).

${ }^{22}$ F. R. de Boer, R. Boom, W. C. M. Mattens, A. R. Meidema, and A. K. Niessen, Cohesion in Metals, Transition Metal Alloys (North-Holland, Amsterdam, 1988).

${ }^{23}$ Y. S. Cho and C. C. Koch, J. Alloys Compd. 194, 287 (1993).

${ }^{24}$ M. L. Swanson, J. R. Parsons, and C. W. Hole, Radiat. Eff. 9, 249 (1971).

${ }^{25}$ F. H. Froes, C. Suryanarayana, K. C. Russell, and C. M. Ward-Close, in Novel Techniques in Synthesis and Processing of Advanced Materials, edited by J. Singh and S. M. Copley (TMS, Warrendale, PA, 1995). 